\title{
Oral Health Knowledge and Behavior of Clinical Medical, Dental And Paramedical Students In Mangalore
}

\author{
Shiraz Usman, Sham S. Bhat, Sharan S Sargod
}

\section{ABSTRACT}

Medical, Dental and Paramedical students play an important role in oral health care and promotion. Learning in these professional institutions becomes ineffective unless it leads to a profound change in student's behavior and attitude towards improvement of their own personal health. This study aims to find out the difference in oral health knowledge and behavior of clinical medical, dental and paramedical students in the Yenepoya Educational Institutions, Mangalore.

\section{Contact Author}

Dr. Sham S. Bhat

E-mail : bhatsham@indiatimes.com

Key words: Oral health knowledge and attitude, Medical, dental and paramedical students.

$\mathrm{O}$ ral health knowledge is considered to be an essential prerequisite for health related behavior, although only a weak association seems to exist between knowledge and behavior in cross-sectional studies, nevertheless studies have shown that there is an association between knowledge and better oral health.(1) Earlier studies have also shown dentist to be lacking in self motivation to practice basic preventive oral health habits.(2) Since clinical professional students specialize in preventive information and health promotion it is important that their own oral health knowledge is good and confirms to professional recommendations.

These professional students come across a great number of patients of different age groups from different backgrounds in their day to day course of study hence with proper knowledge and oral health behavior they can play an important role in oral health education of individuals and group, and act as role models for these patients and community at large. Thus the aim of the present study was to compare the oral health attitude and knowledge among the clinical professional students.

\section{Material and Methods}

Study group included clinical professional students in Yenepoya Educational Institutions.

Clinical professional students included, medical students from $2^{\text {nd }} \mathrm{yr}$ M.B.B.S to internship, dental students from $3^{\text {rd }} \mathrm{yr}$ B.D.S to internship and paramedical i.e. B.Sc Nursing and B.P.T from $1^{\text {st }}$ yr to $3^{\text {rd }}$ yr.
A self administered questionnaire was distributed to 319 medical students, 255 dental students and 369 paramedical students. No information of their academic record was gathered from students .The questionnaire consisted of 15 questions which contained information on their attitudes towards dental care, oral health practice, and knowledge of oral health.

Data collected were entered and proportions were compared using Chi- square test. A 'p' value of less than 0.05 was considered statistically significant . The data analysis was done using SPSS-10 statistical software.

\section{Results and Discussion}

Significant differences were found in 12 of the 15 questions mentioned. Almost a greater majority of professional students

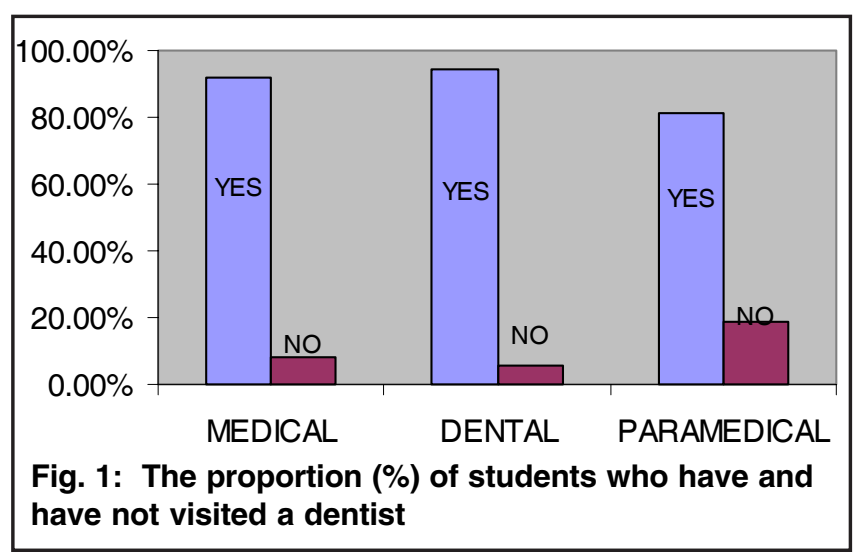




\section{口Medical םDental $\square$ Paramedical}

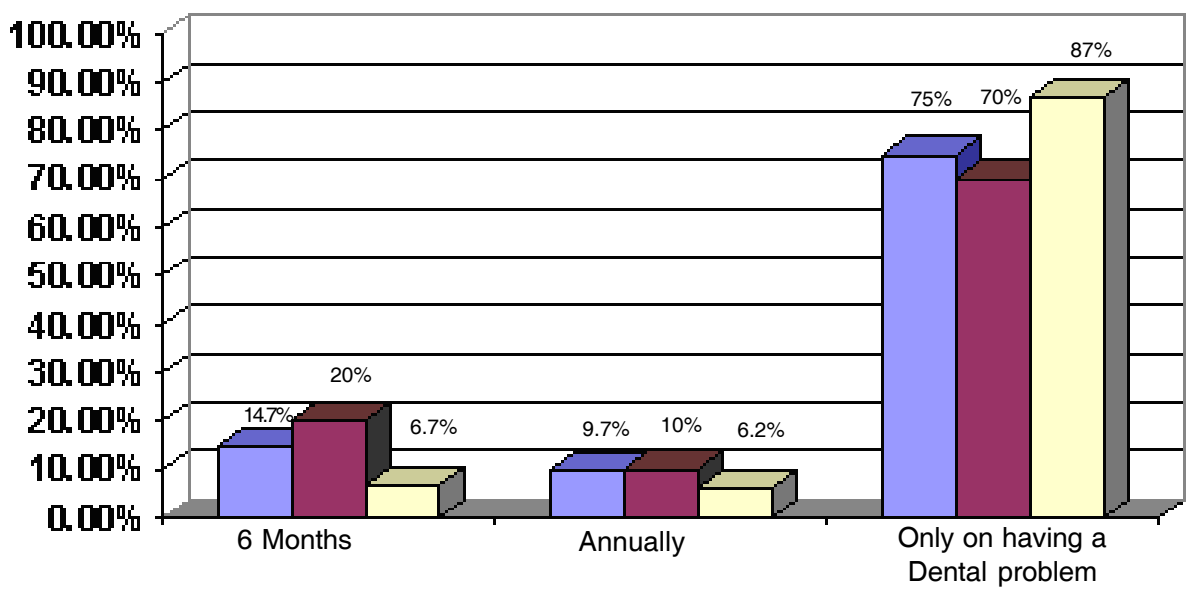

Fig. 2: Frequency of dental visit
A greater portion of medical and paramedical students $(96 \%)$ showed poor knowledge on the role of fluorides in dentifrices as they seem to ignore this fact on selecting dentifrices $(\mathrm{P}<0.001)$.More striking result was a large section of paramedical $(79 \%)$ and medical $(36 \%)$ have never heard of the term flossing to date in comparison to negligible percentage of dental students $(4.7 \%)(\mathrm{P}<0.001)$. Only a small proportion of medical $(20 \%)$, paramedical (12\%) and dental (34\%) thought that visiting dentist was the right way to prevent dental problems while a greater majority held the belief that tooth brushing with paste was the right option $(\mathrm{P}<0.001)$.
$(88.3 \%)$ have visited the dentist (Fig. 1) and dental caries being the most common cause for the visit $(61 \%)(\mathrm{P}<0.001)$. Though not majority of either group worried about visiting a dentist, Paramedical students worried more comparatively (38\%) and pain being most common fear factor $(\mathrm{P}<0.001)$.

It was surprising to observe that apart from $75 \%$ of medical students and $86 \%$ of paramedical students even more than half the dental students $(69 \%)$ put off visiting the dentist till they encountered a dental problem $(\mathrm{P}<0.001)$. (Fig. 2) which co relates with an earlier study comparing the general nursing students with dental hygiene students.(3)
Above all it was satisfactory to find that almost most of the medical (80\%), dental (96\%) and paramedical (85\%) students considers oral health as important as maintaining a good general health $(\mathrm{P}<0.001)$ (Fig. 3).

Oral health knowledge was expected to be good among the clinical dental students in this study, since it is an important content in their professional education as they require this knowledge to educate the patients and the community when they begin working in health care system. However there seems to be areas such as practicing a regular dental visit, flossing, where their attitude had to be improved. Other studies have also shown the same among dental students. $(4,5)$

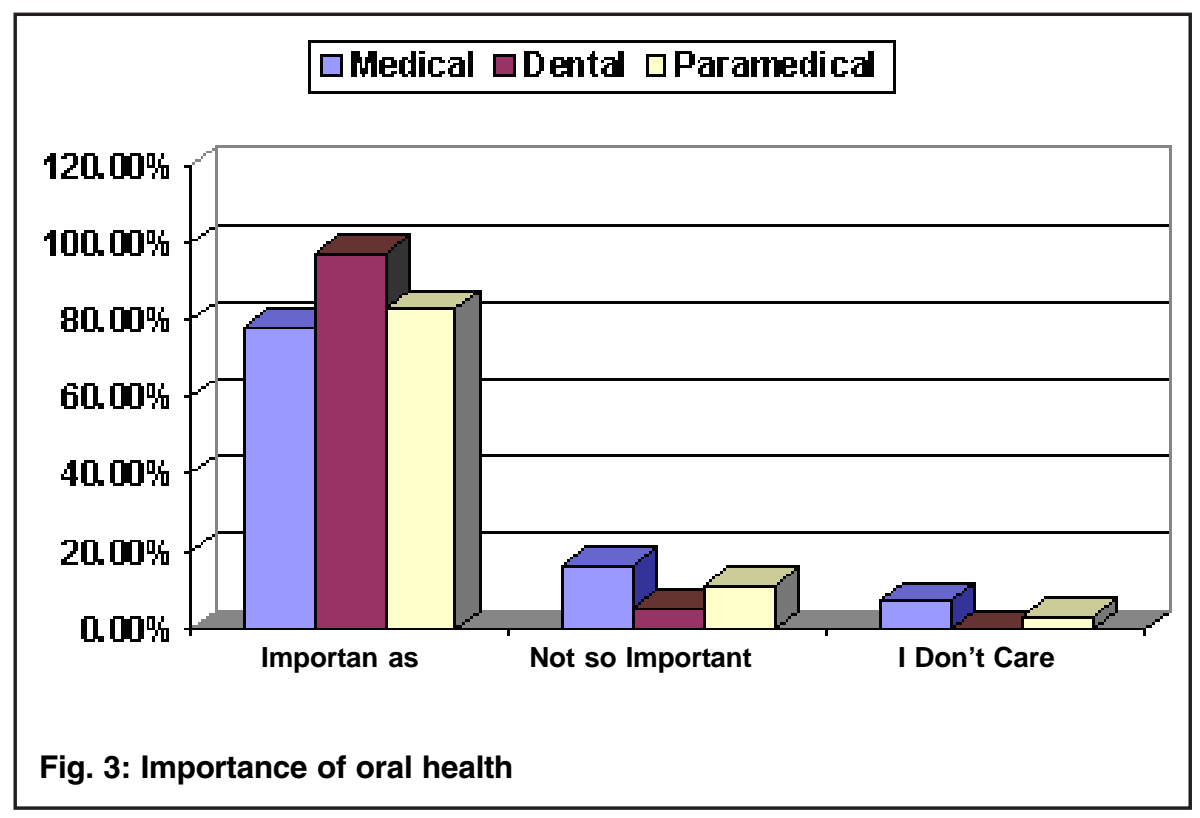

\section{CONCLUSION}

Oral health knowledge and attitude was high among the dental students as it is significant part of their professional education. Clinical medical and paramedical students showed poor oral health knowledge comparatively .Oral health hardly receives any exposure in the medical and paramedical curriculum; hence oral health education must be included in pre-clinical curriculum of medical and paramedical courses. Further research is needed to examine the students clinically for assessing the periodontal and caries status. These professional Students must be encouraged to be a good role model in promoting oral health education among their family, friends and their patients. 


\section{THE AUTHORS}

\section{Shiraz Usman}

Post Graduate Student

Department of Pedodontics and Preventive Dentistry

Yenepoya Dental College

Nithyananda Nagar P.O., Deralakatte, Mangalore- 57501

Email: shirazusman@hotmail.com

\section{Sham S. Bhat}

M.D.S

Professor and Head

Department of Pedodontics and Preventive Dentistry

Yenepoya Dental College, Mangalore

Phone no. : 09448356562

E-mail: bhatsham@indiatimes.com

\section{Sharan S Sargod}

M.D.S

Reader

Department of Pedodontics and Preventive Dentistry

Yenepoya Dental College, Mangalore

\section{REFERENCES}

1. Kawamura M, Yip H.K, Hu D.Y, Komabayashi T. A cross-cultural comparison of dental health attitudes and behavior among freshman dental students in Japan, Hong-Kong and West China.Int Dent J 2001; 51: 159-63.

2. Chattopadhyay A. Self assessed oral health awareness and unmet demands among medical and dental professionals in Calcutta. Community Dent Oral Epidemol 1990;18:163-4.

3. Kawamura M,Ikeda-Nakaoka Y,Sasahara H.An assesement of oral self care level among Japanese Dental hygiene students and general nursing students using the Hiroshima University- Dental Behavior Inventory (HU-DBI). Eur J Dent Edu 2000 May; 4(2):8288.

4. Rong W.S,Wang W.J,Yip H.K .Attitudes of dental and medical students in their first and final years of undergraduate study to oral health behavior. Eur J Dent Edu. 2006 Aug; 10(3):178-81.

5. Al-Wahadani AM,Al-Omiri MK,Kawamura M.Differences in self reported oral health behavior between dental students and dental technology /dental hygiene students in jordan.J Oral Sci.2004 Sep;46(3):191-7. 